\title{
Vidas em movimento: da consideração à ética da diferença
}

\author{
Flávia Rodrigues de Castro* \\ Carolina Moulin ${ }^{\star *}$
}

FASSIN, D. Life: a critical user's manual. Cambridge: Polity Press, 2018.

MACÉ, M. Siderar, considerar: migrantes, formas de vida. Rio de Janeiro: Bazar do Tempo, 2018.

Como pensar a condição migrante e refugiada hoje? As obras de Marielle Macé e Didier Fassin, analisadas nesta resenha, são aproximações críticas ao desafio que a mobilidade internacional apresenta para o campo da reflexão acadêmica e engajamento ativista, particularmente de e com sujeitos que circulam entre políticas de exclusão, confinamento e violência. Fassin possui uma extensa obra dedicada ao tema do refúgio e do sujeito humanitário, em uma contribuição que articula a descrição densa etnográfica e a mobilização de uma arquitetura e aparato normativos e epistêmicos destinados à disciplina e gestão desses corpos. Life consolida essa reflexão, promovendo um giro àquilo que constitui o cerne da questão contemporânea: como pensar e reagir à desigualdade que modula entre seres que merecem viver e aqueles submetidos a condições de exceção, interditados em sua significação sociopolítica e presos em uma espiral disciplinar e de dominação crescentemente globalizada?

\footnotetext{
* Pontifícia Universidade Católica do Rio de Janeiro (PUC-Rio), Rio de Janeiro-RJ, Brasil (flaviacastro.uff@gmail.com; https:// orcid.org/0000-0001-9951-5271).

${ }^{* \star}$ Centro de Desenvolvimento e Planejamento Regional (Cedeplar), Universidade Federal de Minas Gerais (UFMG), Belo Horizonte-MG, Brasil (cmoulin@cedeplar.ufmg.br; https://orcid.org/0000-0002-4176-2234).
} 
Marielle Macé, por seu turno, na esteira de sua crítica literária e contribuição aos estudos de linguagem, tensiona os modos de organização e resposta ao "problema" da presença de refugiados e migrantes no espaço das metrópoles globais e de países centrais. A autora olha para os acampamentos e experiências desses grupos na França para propor uma mirada, que desestabiliza as perspectivas voltadas, de um lado, para a contenção e, de outro, para o voluntarismo salvacionista. Esse processo, para Macé, pode ser compreendido como a abertura existente no movimento que passa da chamada sideração à consideração, isto é, de mover-nos de um estado de atordoamento e paralisia em direção à potência envolvida na ação de levar em conta a vida do outro e, assim, as diferentes formas de vida. 0 que este movimento de consideração pressupõe não é apenas um olhar atento, mas também a abertura de brechas nos modos de acolher e considerar as vidas não como abstração, mas como são de fato vividas apesar de tudo. Para Fassin, este mesmo espaço pode ser compreendido a partir da consideração das vidas desde seu caráter de desigualdade, permitindo aquilo que o autor chama de novas possibilidades de intervenção. 0 movimento proposto por ele seria, portanto, aquele que nos permitiria passar da compaixão ao reconhecimento da injustiça. Mais do que uma escolha teórica, Fassin acolhe este projeto como um imperativo ético e político que, ao partir da perspectiva da desigualdade, cria novas possibilidades de engajamento com as experiências daqueles que são constantemente destituídos na "hierarquia das vidas" (FASSIN, 2018, p. 124).

Tanto Macé quanto Fassin desenvolvem seus textos a partir de fragmentos de experiências que evidenciam algumas formas de vida consideradas pelos autores. Macé inicia sua obra propiciando ao leitor imagens de um campo de migrantes e refugiados em Paris, no chamado cais de Austerlitz, à beira do Sena e abaixo da estação de trem de mesmo nome. Esta imagem traz com ela, segundo a autora, algo de siderante em sua própria localização, que propicia o encontro atordoante entre pontos da cultura, com os mais valorados bens já produzidos, e as vidas vividas em condição de despojamento, em uma destituição que se coloca às margens do Sena, na cidade luz. Nas palavras de Macé (2018, p. 15), então, as “bordas estão em pleno centro", trazendo consigo a tarefa política de lidar com as experiências que se põem lado a lado. Fassin, por sua vez, recorre ao seu extenso trabalho de campo na África do Sul e na França, traçando alguns paralelos entre diferentes narrativas e situações que emergem do contato do autor com aqueles que estão à margem do Estado, especialmente solicitantes de refúgio e imigrantes não documentados. Apesar da pluralidade de experiências tratadas pelo autor, chama a atenção o caráter siderante que Fassin identifica em uma dessas formas de vida: um homem jovem, recluso em seu apartamento, com as cortinas sempre fechadas, no centro de um projeto de habitação em Paris. 0 marroquino, que migrou com a família para a França aos 12 anos, enfrentou dificuldades escolares e empregatícias, fez uso de heroína, tornou-se soropositivo e foi condenado ao encarceramento e à deportação por delitos relacionados ao uso de drogas. Doente, sem documentos nem recursos e com 
medo de ser deportado, o jovem não teve acesso a tratamento médico e faleceu em seu apartamento, ainda recluso, aos 36 anos.

Aquilo que Macé e Fassin percebem como siderante nos fragmentos de experiências que consideram, e que evidenciam diferentes formas de vida, talvez seja o que permite que ambos os autores recorram a Walter Benjamin para o desenvolvimento de suas obras. Para Macé, seria inevitável pensar em Benjamin ao tratar do encontro siderante entre o campo de migrantes e refugiados e os pontos culturais em seu entorno, como a biblioteca nacional da França. A autora nos recorda, assim, não só a importância dos bens e coleções - especialmente de livros - para Benjamin, como também sua violenta destituição em sua fuga da perseguição da Gestapo. Parte da história de Benjamin é marcada, assim, pelos deslocamentos forçados e pela tentativa de salvar seus livros acumulados durante a vida. Macé não deixa passar despercebida, neste cenário que nos atordoa e nos paralisa, outra proximidade em relação ao campo de migrantes em Paris: o campo anexo de Austerlitz, onde funcionava o que a autora chamou de uma "espécie de armazém geral nazista" (MACÉ, 2018, p. 17), em que se reuniam os bens pilhados dos judeus perseguidos e assassinados. Fassin, por outro lado, que analisa não só a morte biológica, mas também a morte social de determinados sujeitos, faz recordar um quadro de Paul Klee, Angelus Novus, comprado por Benjamin e sobre o qual este autor iria escrever em um dos manuscritos que guardava consigo em sua fuga. Sobre a obra de arte, Benjamin escreveu que:

Existe um quadro de Klee intitulado "Angelus Novus". Nele está representado um anjo, que parece estar ao ponto de afastar-se de algo em que crava seu olhar. Seus olhos estão arregalados, sua boca está aberta e suas asas estão estiradas. 0 anjo da história tem de parecer assim. Ele tem seu rosto voltado para o passado. Onde uma cadeia de eventos aparece diante de nós, ele enxerga uma única catástrofe, que sem cessar amontoa escombros sobre escombros e os arremessa a seus pés. Ele bem que gostaria de demorar-se, de despertar os mortos e juntar os destroços. Mas do paraíso sopra uma tempestade que se emaranhou em suas asas e é tão forte que o anjo não pode mais fechá-las. Essa tempestade o impele irresistivelmente para o futuro, para o qual dá as costas, enquanto o amontoado de escombros diante dele cresce até o céu. 0 que nós chamamos de progresso é essa tempestade (BENJAMIN, 1940 apud LÖWY, 2005, p. 87).

Ao refletir sobre aquilo que Macé identifica como um estado siderante, que nos deixaria paralisados e enclausurados, e aquilo que Fassin traz sobre as formas de vida com as quais se engajou durante o trabalho, com suas narrativas que atordoam, tornou-se inevitável lembrar a interpretação de Benjamin sobre Angelus Novus. Conforme nos diz Fassin, é perturbador que ainda tenhamos no presente alguns eventos que, assim como no começo do século XXI, fariam com que o chamado "anjo da história" contemplasse, petrificado, "as formas de vida que os eventos trágicos produzem” (FASSIN, 2018, p. 47). Porém, se o tom da imagem produzida por Benjamin sobre a história e a experiência humana pode ser compreendido como trágico, enfatizando o caráter destrutivo que atravessa a humanidade, não é este mesmo sentido que parece emergir das obras analisadas aqui. Tanto Macé quanto Fassin parecem compor com aquilo que Didi-Huberman (2011) critica 
no lamento ou desistência de Pasolini, ${ }^{1}$ ao declarar o desaparecimento dos vaga-lumes, ou a morte das sobrevivências. Assim, para Didi-Huberman, não seria possível declarar a morte das sobrevivências, mas o que teria desaparecido seria a própria capacidade (neste caso, a capacidade do próprio Pasolini) de ver "aquilo que aparece apesar de tudo" (DIDI-HUBERMAN, 2011, p. 65). Seria preciso, então, poder ver o espaço dos lampejos que é produzido pelas sobrevivências e que "nos ensinam que a destruição nunca é absoluta" (DIDI-HUBERMAN, 2011, p. 85).

O espaço dos lampejos ou a "política das sobrevivências" (DIDI-HUBERMAN, 2011, p. 84) são as brechas que Macé e Fassin procuram desenvolver em seus textos como forma de criar novas possibilidades de engajamento e intervenção. Conforme diz Macé (2018, p. 27, 28), o esforço realizado é em busca de "falar das vidas que se mantêm, que tentam se manter ou têm de se manter em pleno acampamento" e, sobretudo, "falar do movimento não mais de sideração, mas de consideração que deveria também nos animar”. Este movimento de consideração é o que permitiria, segundo Macé, a criação de novas possibilidades e reaproximações com diferentes formas de vida. Já Fassin, ao abordar fragmentos de experiências de refugiados ou imigrantes, solicitantes de refúgio ou estrangeiros não documentados, fala a respeito da importância de tratar destas formas de vida que, apesar de estarem sujeitas a opressões e violências, não se resumem àquilo que se impõe sobre elas. "Sob a forma, a vida permanece”, afirma Fassin (2018, p. 46). Ambos os autores parecem propor, então, o movimento de considerar as vidas que resistem e se mantêm, produzindo o espaço dos lampejos que Didi-Huberman (2011, p. 42) chama de espaço dos "apesar de tudo". A política das sobrevivências, para este autor, nos convoca a reinventar a capacidade de ver aquilo que Pasolini teria declarado como morto. Em outras palavras: "Há sem dúvidas motivos para ser pessimista, contudo é tão mais necessário abrir os olhos na noite, se deslocar sem descanso, voltar a procurar os vaga-lumes" (DIDI-HUBERMAN, 2011, p. 49).

Inserido neste esforço do deslocamento para considerar as formas de vida, Fassin questiona como é possível caracterizar a vida humana dando conta, ao mesmo tempo, das similaridades e diferenças que existem entre elas. Para isso, o autor coloca em tensão produtiva algumas abordagens que se propõem incompatíveis, explorando as relações complexas entre o universal e o particular, a biologia e a biografia, a lei e a prática. A partir da análise dos fragmentos de experiências, Fassin demonstra como todas as condições de exílio com as quais se engajou compartilhavam semelhanças em relação ao seu caráter de vulnerabilidade, ao mesmo tempo que se apresentavam como experiências singulares e ininteligíveis para outros grupos. Para além das tensões entre as

\footnotetext{
${ }^{1}$ Didi-Huberman (2011) dá início à sua obra a partir do engajamento crítico com o texto do cineasta e escritor Pasolini, chamado "O vazio de poder na Itália", publicado em 1975, no qual Pasolini teria teorizado e afirmado o desaparecimento dos vaga-lumes. Segundo Didi-Huberman (2011, p. 25), "trata-se de um lamento fúnebre sobre o momento em que, na Itália, os vaga-lumes desapareceram, esses sinais humanos da inocência aniquilados pela noite - ou pela luz 'feroz' dos projetores - do fascismo triunfante". O desaparecimento dos vaga-lumes no texto de Pasolini diz respeito, então, ao desaparecimento da resistência diante do totalitarismo, conforme diz Didi-Huberman em sua obra.
} 
dimensões transcendentais e antropológicas, haveria ainda uma tensão entre aspectos biológicos e biográficos, que se refletem nas necessidades básicas (comida, abrigo, segurança) dos sujeitos que só podem ser satisfeitas a partir das suas relações com outros atores, construídas durante as trajetórias de vida de cada um daqueles que migram. Por último, a interação complexa entre lei e prática pode ser analisada, segundo o autor, por meio da relação entre a necessidade do status legal no país de destino para fins de acesso a direitos e o emprego de táticas que permitem que os migrantes brinquem com as regras, acomodando-se, de certa forma, aos obstáculos legais impostos.

Ao colocar em diálogo as tensões constitutivas que atravessam e compõem as experiências dos sujeitos, Fassin emprega o conceito de formas de vida e propõe que revisitemos a obra de Judith Butler sobre precariedade. 0 autor retoma, assim, a ideia da precariedade não só como uma condição ontológica e, portanto, compartilhada coletivamente pelos seres humanos, mas também como condição sociopolítica experimentada e distribuída de maneira desigual. Assim, segundo Fassin (2018, p. 43), é importante "distinguir entre a precariedade como uma experiência universal de finitude e, portanto, fragilidade da existência humana, e a precariedade como a condição daqueles expostos à desigualdade, discriminação, injustiça, ou perseguição que ameaça a existência”. A precariedade, ao mesmo tempo que atravessa e marca as vidas de todos os seres humanos, afeta em maior ou menor grau tais vidas de acordo com a desigualdade que as reposiciona na existência em sociedade.

A necessidade de reconhecer tal precariedade, bem como a semelhança e a dessemelhança que acompanham as formas de vida, é também reafirmada por Macé (2018, p. 31) quando afirma que é preciso "experimentar-nos como semelhantes-dessemelhantes [...] Se toda vida é insubstituível (e ela é), não é exatamente porque é única (mesmo que evidentemente o seja), é porque é igual e deveria sempre ser tida como tal". A autora critica, então, e também em diálogo com Butler, a existência de uma hierarquia do luto que faz com que determinadas vidas não sejam enlutadas ou choradas, pois nunca teriam sido consideradas plenamente vividas, em primeiro lugar. Para Macé (2018, p. 38), seria preciso, então, mover-nos em direção a novas possibilidades de considerar as vidas vividas em suas experiências cotidianas e concretas, uma vez que "a consideração reclama antes de tudo o direito das vidas".

Um segundo movimento importante na obra de Fassin, e que está em sintonia com as preocupações expostas por Macé sobre a necessidade da consideração, é a análise que o autor faz das diferentes éticas da vida. Conjugando alguns esforços de reflexão teórica e abordagem empírica, Fassin se desloca e se afasta de um questionamento sobre o que seria o chamado "bem viver" em direção a preocupações com "o modo pelo qual a vida se tornou o bem supremo nas sociedades contemporâneas" (FASSIN, 2018, p. 49). A análise dos casos de imigrantes que sofrem com doenças e problemas de saúde na África do Sul e na França permite que o autor aborde os aspectos sociopolíticos e físico-biológicos envolvidos na valoração das vidas. 0 que Fassin demonstra com suas 
reflexões é uma mudança fundamental nas éticas da vida, com um declínio de seu valor enquanto fenômeno sociopolítico e sua progressiva valoração em termos biológicos. Segundo o autor, se torna mais importante, para fins de concessão de residência ou refúgio, por exemplo, o reconhecimento de uma doença do que de uma perseguição. Em paralelo com a valoração da vida a partir de critérios biológicos, estaria o desenvolvimento do humanitarismo, colocando no centro das ações humanitárias a necessidade de salvar vidas de cenários de guerra, fome, desastres ou epidemias.

A proposta da análise de Fassin é considerar, nas transformações na apreensão da vida e do seu valor, o que é tornado invisível e deixado de lado - isto é, como o movimento de valoração da vida enquanto existência física e biológica obscurece questões de proteção legal e justiça social. Nas palavras do autor, então, “o progressivo reconhecimento da vida física é frequentemente acompanhado por um declínio na importância da vida política, e a legitimidade da emergência humanitária diminui o poder da demanda por justiça social” (FASSIN, 2018, p. 80). A reflexão do autor sobre os perigos em garantir proeminência à vida biológica a despeito dos seus aspectos sociopolíticos parece estar em sintonia com o movimento de consideração proposto por Macé. Embora a autora não direcione suas reflexões aos debates filosóficos sobre éticas da vida, emerge da sua obra a mesma preocupação com políticas humanitárias e sentimentos de compaixão que podem atrapalhar a tarefa política e jurídica de demandar direitos. Assim, para Macé (2018, p. 37), diferentemente da compaixão, “a consideração, por sua vez, é mais política, mais social, menos 'humanitária', se quisermos”. Entender a importância da consideração na obra de Macé é compreender, então, a vida menos nos termos do humanitarismo e mais na luta por direito e justiça, assim como também propõe Fassin.

A centralidade concedida por Fassin às questões de direito e justiça na consideração das vidas conduz o autor à tarefa de analisar "o que a política faz com as vidas humanas” (FASSIN, 2018, p. 85). A última parte de sua obra é dedicada, assim, a pensar as contradições entre "éticas da vida" e "políticas da vida", uma vez que o caráter sagrado das vidas é posto em tensão com a desigualdade que as atravessa e garante um tratamento diferenciado a depender do valor atribuído a cada vida humana. Fassin busca analisar, então, o tratamento político das vidas a partir da lente das ações humanitárias, salientando as disparidades na valoração das vidas situadas no cotidiano da política, desafiando, com isso, a concepção ética da vida como bem supremo. 0 autor também procura ilustrar este processo - que inscreve a desigualdade nos corpos - por meio de uma série de exemplos que demonstram não só como diferentes sociedades atribuíram, historicamente, valores financeiros à vida humana, mas também como a própria morte, física e social, ocorre de maneira desigual e afeta desproporcionalmente certas vidas. Da mesma forma, Macé nos proporciona um exemplo desta política que recai sobre as vidas e determina a morte ao relatar o caso de uma embarcação de migrantes que, em 
2011, "ficou à deriva durante catorze dias numa zona vigiada pela Otan, enviou múltiplos sinais, foi várias vezes identificada, recebeu a visita de um helicóptero e cruzou a trajetória de um navio militar, mas jamais foi socorrida, e na qual 73 migrantes morreram" (MACÉ, 2018, p. 38).

Cada um ao seu modo, Macé e Fassin proporcionam relatos, fragmentos, imagens de experiências que fazem ver que as diferentes formas de vida são "a prova de que se poderia fazer de outro modo, uma vez que se faz de outro modo" (MACÉ, 2018, p. 60). A imagem, como bem diz Didi-Huberman (2011, p. 87), "é pouca coisa: resto ou fissura. Um acidente do tempo que a torna momentaneamente visível ou legível”. Tais imagens, que funcionam como "lampejos de vida" (DIDI-HUBERMAN, 2011, p. 139), trazem a possibilidade política da contestação como demanda por direitos e justiça, bem como a necessária abertura ao que as outras vidas têm a dizer. Vidas que às margens, ou "em pleno centro" (MACÉ, 2018, p. 15), se mantêm como "povos-vaga-lumes, quando se retiram na noite, buscam como podem sua liberdade de movimento, fogem dos projetores do 'reino', fazem o impossível para afirmar seus desejos, emitir seus próprios lampejos e dirigi-los a outros" (DIDI-HUBERMAN, 2011, p. 155). É possível ler as obras de Macé e Fassin como compondo com este esforço de produção de brechas que fazem aparecer aqueles que são tornados invisíveis, que forjam seu movimento apesar de tudo, e nos convocam a produzir "uma comunidade do desejo, uma comunidade de lampejos emitidos, de danças apesar de tudo, de pensamentos a transmitir. Dizer sim na noite atravessada de lampejos e não se contentar em descrever o não da luz que nos ofusca" (DIDI-HUBERMAN, 2011, p. 155).

\section{Referências}

DIDI-HUBERMAN, G. Sobrevivência dos vaga-lumes. Belo Horizonte: Editora UFMG, 2011.

LÖWY, M. Walter Benjamin: aviso de incêndio. Uma leitura das teses "Sobre o Conceito de História”. São Paulo: Boitempo, 2005.

\section{Sobre as autoras}

Flávia Rodrigues de Castro é doutoranda em Relações Internacionais pelo Instituto de Relações Internacionais (IRI) da Pontifícia Universidade Católica do Rio de Janeiro (PUC-Rio) e mestre em Estudos Estratégicos da Defesa Nacional e da Segurança Internacional pela Universidade Federal Fluminense (UFF).

Carolina Moulin é PhD em Ciência Política pela McMaster University (Canadá). Professora do Centro de Desenvolvimento e Planejamento Regional (Cedeplar), da Universidade Federal de Minas Gerais (UFMG) e secretária-executiva da Associação Brasileira de Relações Internacionais. É professora colaboradora do Instituto de Relações Internacionais (IRI) da Pontifícia Universidade Católica do Rio de Janeiro. 


\title{
Endereço para correspondência
}

\author{
Flávia Rodrigues de Castro \\ IRI/PUC-Rio \\ Rua Marquês de São Vicente, 225, Vila dos Diretórios, casa XX, Gávea \\ 22451-045 - Rio de Janeiro-RJ, Brasil \\ Carolina Moulin \\ UFMG/Face \\ Avenida Presidente Antônio Carlos, 6627, Pampulha \\ 31270-901 - Belo Horizonte-MG, Brasil
}

Recebido para publicação em 18/10/2019

Aceito para publicação em 23/10/2019 